\title{
Peningkatan Kualitas Pelayanan Pemasaran Terhadap Kepuasan Pelanggan Pizza Hai Dengan Menggunakan Aplikasi GoFood
}

\author{
Dewi Purwanti, Husnia Ika Ernawati \\ Program Studi Ilmu Administrasi Bisnis, Fakultas Ilmu Sosial dan Politik, \\ Universitas Yudharta Pasuruan \\ E-mail: dewi98purwanti@gmail.com, hania163005@gmail.com
}

\begin{abstract}
Abstrak
Kualitas pelayanan merupakan faktor dan akar penting yang mampu memberikan kepuasan bagi pelanggan. Semakin baik kualitas pelayanannya semakin tinggi tingkat kepuasan pelanggan, dengan kinerja yang baik maka akan menciptakan pelayananyang baik sehingga pelanggan akan loyal kepada produk kita. Pelanggan sebagai konsumen dalam melakukan pembeliaan barang telah melalui tahapan-tahapan terlebih dahulu, seperti memperoleh informasi melalui iklan atau referensi dari orang lain (word of mouth), kemudian membandingkan produk dengan produk lain yang sejenis. Metode dalam kegiatan ini adalah memberi informasi dan cara-cara memasarkan produk secara online dengan menggunakan aplikasi GoFood. Hasil dari kegiatan ini adalah pemilik usaha pizza hai sudah memiliki akun di aplikasi GoFood untuk meningkatkan pemasaran, dan penataan layout toko lebih rapi dan menarik. Saran dari kegiatan ini adalah pemilik usaha pizza hai bisa menambah karyawan disaat ada banyak pesanan, agar para konsumen tidak menunggu lama, agar kualitas pelayanan tetap baik dimata para konsumen, sehingga mereka bisa tetap loyal. Dan meningkatkan kinerja pemasaran di aplikasi GoFood, agar penjualan lebih meningkat dan menggunakan aplikasi GoFood semaksimal mungkin.
\end{abstract}

Kata kunci: kualitas pelayanan, brand image, kepuasan pelanggan

\begin{abstract}
Service quality is an important factor and root that is able to provide satisfaction for customers. The better the quality of service is the higher the level of customer satisfaction, with good performance it will create a good service so that customers will be loyal to our products. Customers as consumers in conducting goods goods have gone through prior stage stages, such as obtaining information through advertisements or references from others (word of mouth), then compare products with other similar products. The method in this activity is to provide information and ways to market products online using the Gofood application. The results of this activity are Pizza Hai's business owners already have an account in the Gofood application to improve marketing, and structuring the store layout are neater and attractive. Suggestions from this activity are Pizza Hai business owners can add employees when there are many orders, so that consumers do not wait long, so that the quality of service is still in the eyes of consumers, so they can remain loyal. And improve marketing performance in Gofood applications, so that sales are increasing and using Gofood applications as much as possible.
\end{abstract}

Keywords: Service Quality, Brand Image, Customer Satisfaction

http://ejournal.urindo.ac.id/index.php/PAMAS

Article History :

Submitted 08 Januari 2021, Accepted 26 Oktober 2021, Published 31 Oktober 2021 
Jurnal Pelayanan dan Pengabdian Masyarakat (PAMAS)

\section{PENDAHULUAN}

Perkembangan teknologi komunikasi telah melalui perubahan yang cukup signifikan dari tiap generasi. Terbukti dengan munculnya berbagai macam perangkat telekomunikasi dengan teknologi tingkat tinggi. Teknologi komunikasi yang saat ini menjadi trend di masyarakat adalah smartphone (Wati, Imbayani and Ribek, 2020). Produsen smartphone melihat sebuah fenomena bahwa pentingnya smartphone bagi masing-masing individu di Indonesia, sehingga membuat para produsen smartphone berlomba-lomba untuk memenuhi kebutuhan para pelanggannya. Maka dari itu, kepuasan pelanggan adalah hal penting untuk diperhatikan. Meningkatkan kualitas pelayanan bagi konsumen sangatlah penting, karena kualitas pelayanan merupakan faktor yang mampu memberikan kepuasan bagi pelanggannya yang terkait dengan hasil perilaku konsumen dari mulut kemulut seperti rekomendasi, keluhan konsumen terhadap produk yang dibeli. Banyak sekali bisnis makanan dan minuman cepat saji. Mereka berlomba-lomba dalam menarik minat pelanggan untuk membeli produk mereka. loyalitas merupakan kesetiaan seorang konsumen terhadap suatu perusahaan, produk atau jasa yang melakukan pembelian atas produk tersebut secara berulang-ulang. Dimana pelanggan yang loyal dapat menambah keuntungan yang besar bagi perusahaan. Loyalitas pelanggan juga terbentuk karena adanya kualitas layanan yang baik, brand image serta kepuasan pelanggan terhadap produk atau jasa perusahaan (Fajarianto, Lubis and Saryadi, 2013).

Banyak cara yang bisa dilakukan untuk menarik minat pelanggan. Misalnya, dengan memberikan diskon harga, promosi di media sosial, dan sebagainya. Salah satu cara yang bisa digunakan adalah dengan memberi pelayanan yang baik ke pelanggan sehingga dapat menimbulkan kepuasan pelanggan yang membeli produk.

Di kota Pasuruan banyak sekali bisnis makanan dan minuman cepat saji. Salah satunya di desa Gading kecamatan Winongan banyak bisnis restoran cepat saji, seperti salah satunya di "Pizza Hai" yang merupakan salah satu usaha yang memproduksi berbagai macam bakery dan snack. Pizza Hai Berdiri pada tahun 2015 secara online dan hanya memproduksi Pizza dengan berbagai varian, dan pada tahun 2017 baru membuka outlet "Pizza Hai" yang pemasarannya tidak hanya secara online melainkan juga offline.

Tempatnya yang nyaman dan bersih serta pelayanannya ramah. Sekarang tidak hanya memproduksi dan menjual menu Pizza saja, tapi banyak berbagai menu yang dijual seperti bolen, kue kering dan aneka frozen food. Namun pengerjaan produk masih dilakukan secara sederhana dan manual, tetapi meskipun demikian produk tersebut sudah memiliki Sertifikat Produksi Pangan - Industri Rumah Tangga (SPP-IRT) atau Izin Produk Industri Rumah Tangga (PIRT). 
Dalam memasarkan produknya, produsen memasarkannya secara online yaitu melalui facebook dan instagram. Menurut kami dalam pandemi Covid sekarang butuh dilakukannya pemasaran produk tidak hanya melalui facebook dan instagram melainkan juga perlu dilakukan pemasaran melalui aplikasi GoFood, agar pelayanannya lebih efektif dan efisien.

\subsection{Rumusan Masalah}

a. Kualitas pelayanan dan Brand Image sangat berpengaruh terhadap kepuasan pelanggan

b. Produsen hanya melakukan promosi di media sosial melalui facebook dan instagram sehingga belum menjangkau ke konsumen yang belum mengerti media internet.

c. Produsen kurang paham bagaimana cara memperluas pemasaran secara online maupun offline.

\subsection{Tujuan}

Kegiatan ini bertujuan untuk membantu meningkatkan kualitas pelayanan dan dan brand image terhadap kepuasan pelanggan pizza hai, dengan cara memberikan informasi dan cara-cara memasarkan produk menggunakan aplikasi GoFood.

\subsection{Manfaat}

Kita bisa berbagi ilmu, serta menerapkan ilmu pemasaran dan cara meningkatkan pelayanan terhadap pelanggan salah satunya dengan menggunakan aplikasi GOJEK, dan GOFOOD.

\section{METODE}

Dalam pelaksanaan kegiatan ini dilakukan dengan melakukan survey terlebih dahulu, kemudian melakukan wawancara dengan pemilik usaha pizza hai. Serta dalam kegiatan ini menggunakan metode pendekatan kualitatif. Metode dalam pengabdian ini dapat dilihat pada gambar 1. Pelaksanaan kegiatan PKN. 


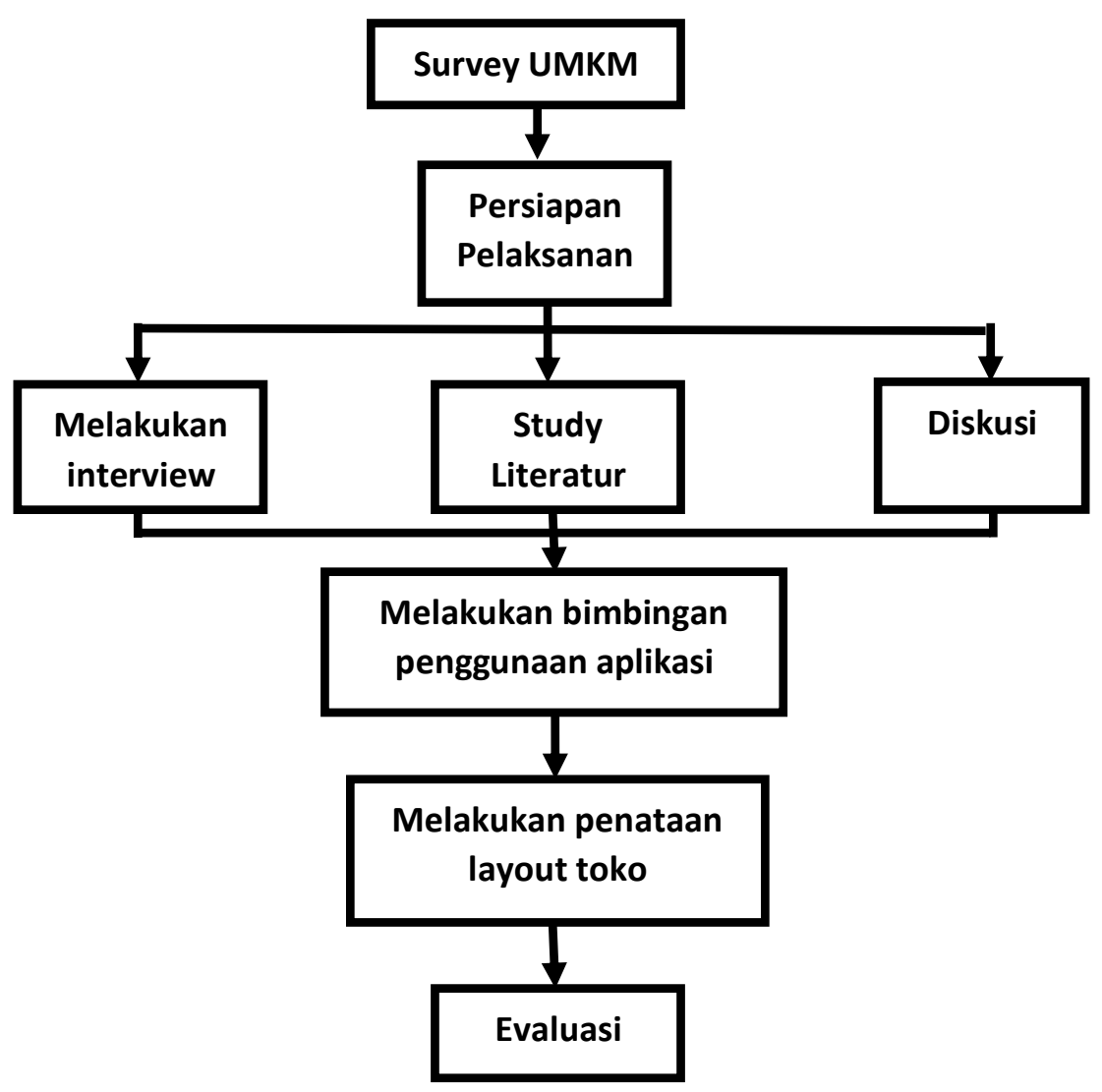

Gambar 1. Pelaksanaan kegiatan PKN

Kegiatan pertama yang dilakukan adalah melakukan persiapan dimana kelompok pengabdian melakukan survey terlebih dahulu untuk melihat kondisi di lapangan, dan mencari permasalahan yang dihadapi oleh pemilik usaha pizza hai dalam meningkatkan kualitas pelayanan dan brand image terhadap kepuasan pelanggannya. Kedua, yaitu pelaksanaan kegiatan, pengabdian melakukan kegiatan mencari solusi bagaimana cara meningkatkan kualitas pelayanan dan brand image di usaha pizza hai. Dan terakhir adalah melakukan evaluasi atas hasil yang telah dicapai oleh peserta pengabdian.

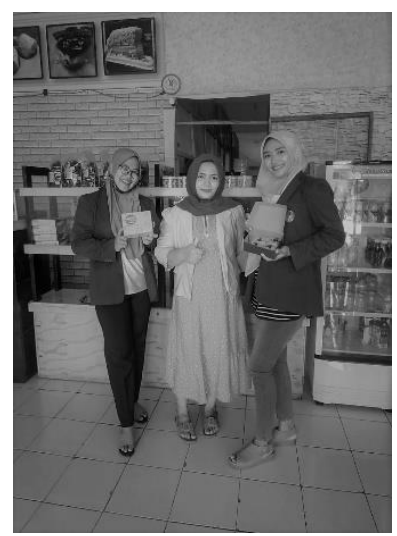

Gambar 2. Obsevasi dan penataan layout toko 


\section{HASIL DAN PEMBAHASAN}

Kegiatan PKN (Praktek Kerja Nyata) yang kami laksanakan berlangsung selama kurang lebih 1 bulan, yang dimulai dari 1 Desember 2020 sampai dengan 31 Desember 2020. Kegiatan PKN ini kami laksanakan dengan berfokus pada permasalahan aspek pelayanan dan aspek pemasaran. Kegiatan awal yang kami lakukan mulai dari melakukan sesi interview dengan pemilik Pizza Hai dan juga melakukan diskusi mengenai rencana kami yang akan melakukan pelatihan peningkatan kualitas pelayanan dan pemasaran secara online dengan menggunakan aplikasi GoFood. Pelaksanaan kegiatan diawali dengan koordinasi dengan pemilik usaha Pizza Hai. Salah satunya kita memberikan pendampingan dan pelatihan dalam penggunaan aplikasi GoFood.

Pada pelaksanaan pendampingan dan pelatihan pada pemilik usaha Pizza Hai, agar dapat mengoperasikan aplikasi GoFood. Pelaksanaan pendampingan dan pelatihan dimulai dari memberikan pemahaman dan pengetahuan tentang bagaimana cara menggunakan aplikasi GoFood sampai pemilik usaha Pizza Hai mampu melakukan penggunaan aplikasi GoFood secara maksimal untuk peningkatan pemasarannya. Kemudian kami melakukan penataan layout toko dengan rapi dan juga menarik pada produk yang sudah siap dijual ke dalam etalase toko.

Ada beberapa rincian dalam melakukan kegiatan ini yaitu:

1. Melakukan sesi interview dengan pemilik usaha Pizza Hai, terkait pemasaran produk-produk yang dijual melalui media online seperti: promosi, memberikan diskon atau potongan harga terhadap konsumen yang membeli dalam jumlah banyak.

2. Melakukan sesi diskusi dengan pemilik usaha Pizza Hai mengenai jadwal rencana yang akan kami lakukan untuk pelatihan dan pendampingan mengenai penggunaan aplikasi GoFood.

3. Pelaksanaan pelatihan dan pendampingan dalam menggunakan aplikasi GoFood dihadiri oleh 3 orang karyawan dan 2 orang owner di usaha Pizza Hai. Materi-materi yang kami sampaikan dalam pelatihan dan pendampingan ini yaitu:

a. Memberikan penjelasan dan kelebihan mengenai penggunaan pemasaran melalui aplikasi GoFood.

b. Menjelaskan cara bagaimana membuat dan menggunakan aplikasi GoFood, untuk memasarkan produk-produk agar lebih banyak lagi konsumen yang mengetahui produk yang dijual.

4. Melakukan pendampingan penggunaan aplikasi GoFood, adapun langkah-langkah yang kami lakukan yaitu:

a. Download aplikasi Go Food di PlayStore, lalu pilih daftar Go Food, klik buka restauran baru milik pribadi, pilih kota tempat Anda membuka restoran tersebut. 
b. Masukkan nama pemilik usaha di kolom pengguna, lalu email dan nomor ponsel yang masih aktif, klik buat akun. Kode konfirmasi akun akan dikirim ke nomor ponsel yang telah didaftarkan.

c. Masukan nama restoran, lalu lanjut ke pilih informasi restoran seperti nama jalan. Atur titik lokasi restoran secara akurat, gunakan bantuan google maps untuk mencari titik lokasi yang paling mendekati. Pilih identitas pemilik, masukkan nomor telepon pemilik usaha, klik upload dan foto KTP .

d. Masukkan nomor KTP di kolom yang sudah disediakan. Klik centang di kolom NPWP klik upload foto kartu NPWP. Masukkan nomor dan nama yang ada pada NPWP. Klik simpan.

e. Pilih informasi rekening bank. Klik panah di kolom nama bank dan pilihlah bank yang Anda gunakan. Masukkan nomor rekening juga nama pemilik rekening. Klik verifikasi jika pemilik rekening berbeda dengan pemilik restoran.

f. Masukkan nama pemilik sesuai KTP dan nama pemegang rekening bank. Klik centang dan upload surat kuasa, klik simpan. Pilih informasi pajak dan lainnya,

g. Masukkan info tarif pajak PB1, tarif pelayanan dengan maksimal 10\%. Klik simpan. Jika semua data sudah lengkap, klik lanjut. Klik kirim data usaha. Pendaftaran selesai Anda hanya perlu menunggu data diproses oleh pihak GOJEK.
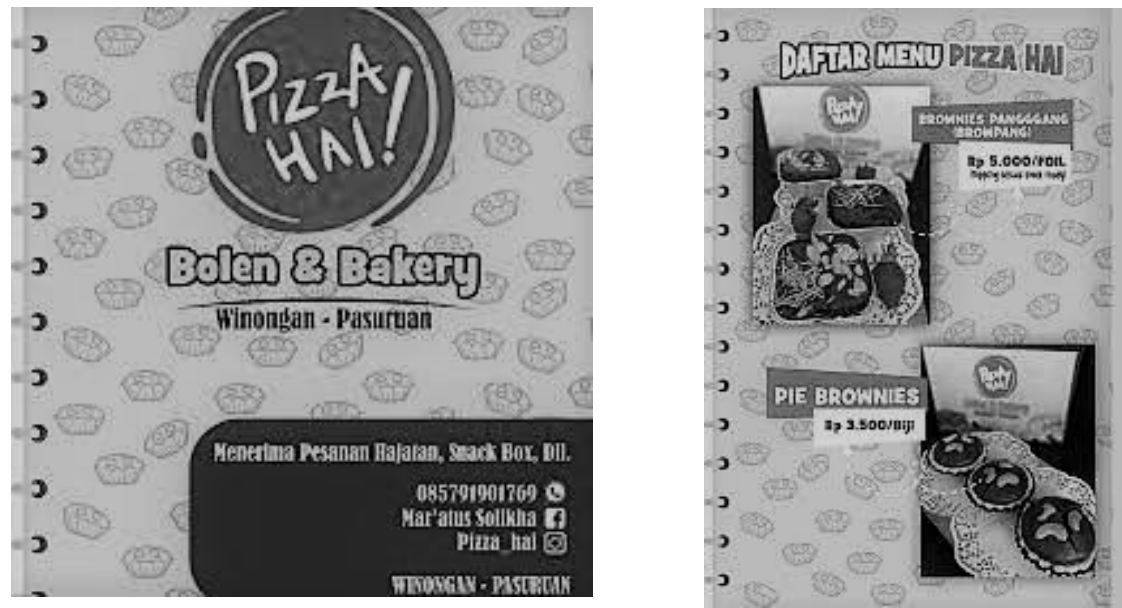

Gambar 3. Logo dan daftar menu Pizza Hai

\section{KESIMPULAN}

Pelaksanaan kegiatan pengabdian di usaha Pizza Hai daerah Gading, Winongan, Pasuruan. Oleh Program Studi Administrasi Bisnis, Fakultas Ilmu Sosial dan Politik, Universitas Yudharta Pasuruan. Memberi dampak positif bagi bisnis usaha pizza hai di tengah pandemi Covid-19. Dengan kami memberikan solusi terhadap permasalahan yang dihadapi oleh pemilik usaha pizza hai, Dengan cara mengenalkan bagaimana cara memasarkan produk melalui aplikasi GooFood 
dan pemasaran secara online di tengah pandemi covid-19 ini. Agar pemilik usaha pizza hai bisa menggunakan dan memanfaatkan aplikasi GoFood dengan semaksimal mungkin untuk meningkatkan pemasaran mereka. Dan kami juga menata layout dengan semenarik mungkin dan rapi agar para konsumen merasa nyaman dan puas saat datang untuk membeli produk yang dijual. Brand image yang dimiliki usaha pizza hai, menunjukkan bahwa kepuasan konsumen sangat berpengaruh baginya. Meningkatkan kualitas pelayanan bagi konsumen sangatlah penting, karena kualitas pelayanan merupakan faktor yang mampu memberikan kepuasan bagi pelanggannya yang terkait dengan hasil perilaku konsumen dari mulut kemulut seperti rekomendasi, keluhan konsumen terhadap produk yang dibeli. Salah satu cara yang bisa digunakan adalah dengan memberi pelayanan yang terbaik. Pengaruh Kualitas produk terhadap konsumen Kepuasan pelanggan berawal dari penilaian konsumen terhadap kualitas produk atau jasa yang diterimanya (persepsi) berdasarkan harapan yang telah terkonsep dalam pikirannya. Kualitas produk sangat berpengaruh terhadap konsumen, dari berbagai macam produk tersebut memiliki kelebihan dan kekurangan masing-masing, konsumen tidak hanya memilih produk tapi mereka juga cermat dan hati-hati dalam menentukan pilihannya sesuai dengan kemampuan, keinginan dan kebutuhannya.

\section{DAFTAR PUSTAKA}

Afnina, A. and Hastuti, Y. (2018) 'Pengaruh Kualitas Produk terhadap Kepuasan Pelanggan', Jurnal Samudra Ekonomi dan Bisnis, 9(1), pp. 21-30. doi: 10.33059/jseb.v9i1.458.

Fajarianto, B., Lubis, N. and Saryadi, S. (2013) 'Pengaruh Kualitas Pelayanan Dan Brand Image Terhadap Loyalitas Pelanggan Melalui Kepuasan Pelanggan (Studi Kasus Pada Cv. Ahass Sahabat Sejati Motor Tembalang Semarang)', Jurnal IImu Administrasi Bisnis S1 Undip, 2(2), p. 103079.

Wati, N. M. D. W. K., Imbayani, I. G. A. and Ribek, P. K. (2020) 'Pengaruh Kualitas Pelayanan, Brand Image, Dan Kepercayaan Terhadap Kepuasan Konsumen Pada Pt Prodia Widyahusada', 1(April), pp. 108-119.

Familiar, K., \& Maftukhah, I. (2015). Pengaruh Kualitas Produk Dan Kualitas Pelayanan Terhadap Loyalitas Pelanggan Melalui Kepuasan Pelanggan. Manajement Analysis Journal, 348354.

Abdi, M., \& Febriani, R. (2020). Pengaruh Kualitas Produk dan Kualitas Pelayanan Terhadap Kepuasan Pelanggan. Jurnal Manajemen dan Bisnis FEB UNBAJA. 
Nurmasari, D., El, M., \& Muharram, H. (2018). Pengaruh Harga Dan Kualitas Pelayanan Terhadap Kepuasan Pelanggan Pada Rumah Makan Sidempuan Medan. Jurnal Manajemen Tools.

Oktarini, R. (2019). Pengaruh Kualitas Pelayanan Dan Harga Terhadap Kepuasan Pelanggan Pengguna Jasa Aplikasi Gojek di Kota Tanggerang. JURNAL ILMIAH ILMU SEKRETARI, 248-256.

Budi, U., Septiani, F., \& Risnalinda. (2020). Pengaruh Kualitas Layanan Terhadap Kepuasan Pelanggan Starbucks Coffee Plaza Kampung Kemang. Jurnal Pemasaran Kompetitif, 4047.

Gofur, A. (2019). Pengaruh Kualitas Pelayanan dan Harga Terhadap Kepuasan Pelanggan. Jurnal Riset Manajemen Dan Bisnis, 37-44. 